\title{
Tongue base schwannoma; a literature review with a new case presentation
}

\author{
Review Mohammed Elrabie Ahmed', Mahmood Hamed', Mostafa ElTaher', Mohammed Abd- \\ Article Elmateen Moussa ${ }^{1}$, Ahmed Ahmed ${ }^{2}$ \\ ${ }^{1}$ Otorhinolaryngology, Head and Neck surgery department, ${ }^{2}$ Pathology department, Sohag \\ faculty of Medicine, Sohag University, Egypt.
}

\begin{abstract}
Head and neck schwannomas represent a considerable percentage of extracranial schwannomas. However, intraoral locations are very rare. Schwannomas of the tongue base have been sporadically reported. The exceedingly paucity of literature reports in this location made them usually skipped out when evaluating a tongue base mass. In this work, we aimed to review the literature about this tumor and to report a new case.

A comprehensive review in English literature of tongue base schwannomas was done with extraction of the related articles and descriptive analysis of the collected data. Also, we presented a new case of 20-year old girl that presented with a slowly enlarging mass of the tongue over 11 years duration. CT and MRI revealed a large well-defined tongue base mass. Biopsy revealed schwannoma. Transoral complete resection with safety margins was done.

Forty-three cases have been reported in literature with slight female predominance. Transoral approach was the commonest approach $(76.7 \%$ ) with the maximal diameter of schwannoma removed transoral was $7.9 \mathrm{~cm}$.

In conclusion; despite their rarity, tongue base schwannomas should be included when ever a benign swelling is suspected. Transoral approach is still the standard approach with the least morbidities and best functional outcomes.
\end{abstract}

Key Words: Lingual, neurilemmoma, neurogenic tumor, schwannoma, tongue base.

Received: 11 March 2018, Accepted: 17 May 2019

Corresponding Author: Mahmood A. Hamed, MD, Otorhinolaryngology, Head and Neck surgery department, Sohag faculty of Medicine, Sohag University, Egypt, Tel.: 01097476649, E-mail: mahmoodhamed8@gmail.com

ISSN: 2090-0740, July 2019 Vol.20, No.2

\section{INTRODUCTION:}

Schwannomas (neurilemmomas) are benign, slowly growing, single, painless and encapsulated neurogenic tumors. The etiology is uncertain; however, it is basically neuroectodermal in origin arising from the proliferation of Schwann cells of the peripheral, autonomic and cranial nerves. Only $50 \%$ have identified the associated peripheral nerve ${ }^{[1]}$.

This lesion is not usually considered in the differential diagnosis of numerous benign epithelial and connective tissues growth affecting the tongue ${ }^{[2]}$. The cornerstone for its diagnosis is definitive histopathological examination ${ }^{[3]}$. In this article, we reviewed the literature about this tumor particularly in tongue base region. In addition, we reported a new case.

\section{MATERIALS AND METHODS}

This study complies with regional and institutional ethical guidelines and with declaration of Helsinki. A written informed consent was obtained from our case for her participation.
We conducted a comprehensive review via Medline/ Pubmed research using the keywords "Schwannoma; Neurilemmoma; Neurogenic tumor; Lingual; Tongue base". Only full English articles with confirmed histopathological diagnosis as schwannoma were selected. Data were analyzed as regard the patients' demographics including the sex, age, and clinical presentation. In addition, the tumor was analyzed as regard size and surgical treatment approaches and modalities.

\section{RESULTS}

\section{Case report:}

A 20-year-old female presented with slowly progressive foreign body sensation, muffled voice, dysphagia and snoring for eleven years duration. There was neither a history of breathing difficulties or paresthesia or pain during swallowing, nor chocking, aspiration, nasal regurgitation or bleeding from the mouth. The patient was healthy, non-smoker with unremarkable past medical and family history.

On examination, a non-ulcerating mass was seen in 
the left side of the tongue base and its lower limit cannot be assessed. Mobility of the tongue and soft palate were normal. On palpation, it was firm, non-tender, with no bleeding on touch, not attached to surrounding tissue. Head and neck examination was otherwise normal. Nasofiberoptic laryngoscopy confirmed the findings and the lesion was reaching vallecula pushing epiglottis forwards with intact mucosal covering while the rest of the oropharynx, larynx and hypopharynx were normal.

CT scan of neck with contrast enhancement has showed superficial, well defined soft tissue lesion, involving the base of tongue on the left side and left tonsillar pillar with no infiltration of adjacent tissue and partial obliteration of oropharyngeal airway. Magnetic resonance (MR) imaging has demonstrated a well-circumscribed mass, uniform isointense to the surrounding muscles in T1 (Fig.1), heterogeneously enhancing hyperintense with a fascicular sign on T2 (Fig.2) and markedly enhanced after intravenous administration of gadolinium DTPA (Fig.1). The mass was measured approximately $6.5 \times 4.3 \times 3.5 \mathrm{~cm}$, completely obliterating the vallecula with downward displacement of epiglottis and upward displacement of tongue base.
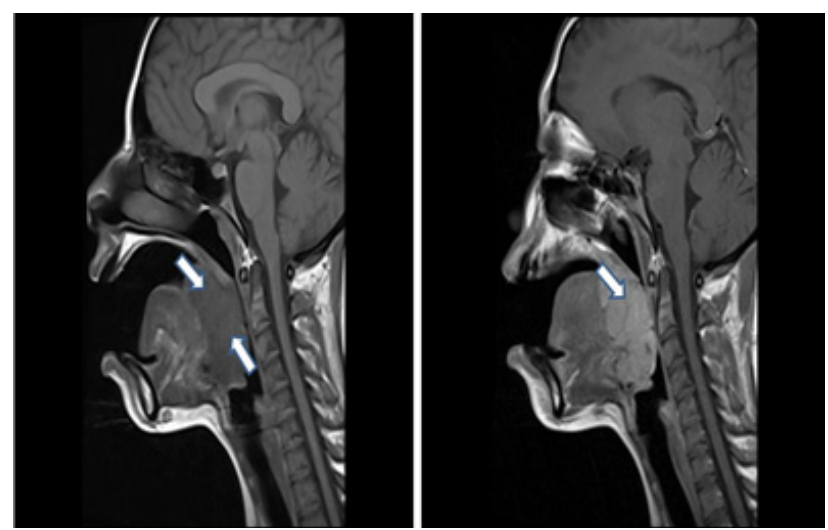

Fig. 1: T1 weighted image MRI sagittal plane without (A) and with (B) contrast showing isointense mass (A) that became hyperintense with contrast enhancement (B).

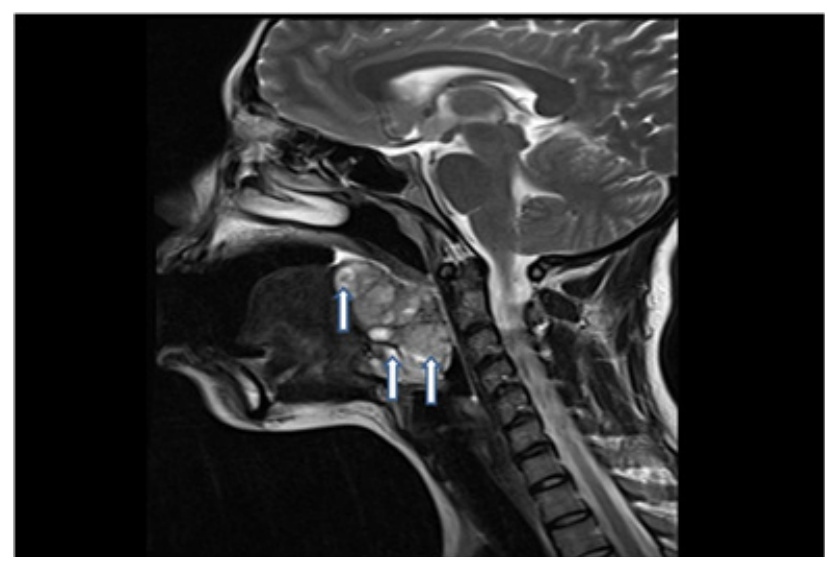

Fig. 2: T2 weighted image MRI sagittal plane showing the characteristic fascicular sign suggesting a lesion of neurogenic origin.
After obtaining proper informed consent and all routine investigation results were within normal limits. Trans-oral biopsy was taken under local anesthesia and the lesion was diagnosed as a schwannoma.

An elective preoperative mid tracheostomy was done under local anesthesia. The patient was anesthetized through the tracheostomy. Cheek and Lip Retractors were placed with tongue traction suture to expose the tumor. It was held by a Luc's forceps and dissection from the tongue using with bipolar and scissor started from the anterior margin of the tumor and continued posteriorly till the tumor is removed. The lesion was submucosal, well encapsulated and with a good cleavage plane. No significant intraoperative bleeding was encountered. The bed of the tumor was primarily sutured to maintain hemostasis.

Nasogastric tube was required. Grossly the mass was well encapsulated and had firm gray white cut surface. Histopathological examination of surgical specimen confirmed the diagnosis of schwannoma with negative safety margins (Fig.3).

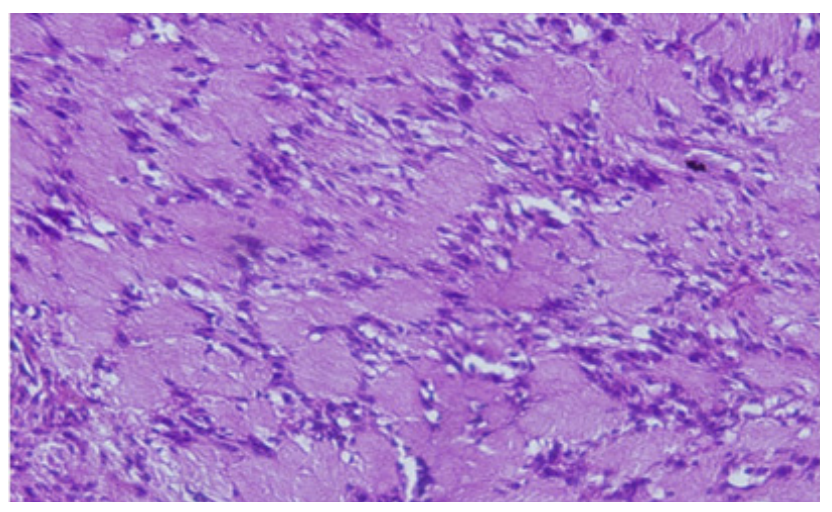

Fig. 3: Histologic examination revealed a relatively cellular mitotically inactive neoplasm composed of spindle shaped cells with moderate pale eosinophilic cytoplasm and short nuclei arranged in a characteristic palisading fashion with organoid arrangement (Verocay bodies). (H\&E stain; X 40).

The postoperative course was uneventful and patient recovered well. The mobility of the tongue was good. Postoperatively, there were no complaints related to swallowing, breathing and speech. Nasogastric tube and tracheostomy were removed on 5th day. Patient was discharged home after 8 days of surgery. Patient was followed up regularly for 6 months on monthly basis during which she remained symptom free and no evidence of recurrence.

\section{Literature review results}

From 1964 until 2017, we have found 33 articles for tongue base schwannomas ${ }^{[2-34]}$. We had 43 patients with an age ranging from 6 to 68 years (average 28.6 years). 
Of these patients, 17 were males $(39.5 \%)$ and 26 were females $(60.5 \%)$

Progressive dysphagia, globus sensation and painless swelling were the most frequent presentations (93\%). Other presentations include odynophagia, frequent hawking, pain, breathing difficulty, snoring and change of voice or asymptomatic were seen nearly in one fourth of patients $(25.6 \%)$. Size of the lesion was ranging from 1.2 to $7.9 \mathrm{~cm}$ in its maximum diameter.

Transoral approach was the commonest one representing 33 patients $(76.7 \%)$ with the maximal diameter of schwannoma removed transoral was $7.9 \mathrm{~cm}$. While, open approaches were suprahyoid or transhyoid lateral pharyngotomy in 7 patients $(16.3 \%)$, one patient by submandibular pull through approach $(2.3 \%)$ and two patients by midline mandibulotomy and tongue split.

\section{DISCUSSION:}

Schwannomas are rare neurogenic tumors that also known as neurinomas or neurilemomas. In 1910, Verocay first described nerve sheath tumors that were termed as "neurinomas". In 1935, it was proposed that these tumors were derived from nerve sheath and not from the neurons, hence they were termed 'Neurilemmomas. The Currently used term is schwannoma. They arise from Schwann cells that comprise the myelin sheaths surrounding peripheral nerve which is thought to be the common precursor for most nerve sheath tumors ${ }^{[1,35,36]}$.

Approximately $25 \%$ of all schwannomas occur in the head and neck. Intraoral schwannoma accounts for $1 \%$ of all head and neck schwannomas and commonly seen at the tongue $(66 \%$ in anterior third of the tongue vs $34 \%$ in the posterior two thirds) followed by palate, floor of mouth, buccal mucosa, gingiva, lips and the vestibular mucosa in descending manner ${ }^{[37,38]}$.

Schwannomas may occur at any age but is most commonly between the $4^{\text {th }}$ and $6^{\text {th }}$ while oral cavity between $2^{\text {nd }}$ and $4^{\text {th }}$ decades of life. This was in accordance with our study which revealed that 24 patients $(55.8 \%)$ were presented between $2^{\text {nd }}$ and $4^{\text {th }}$ decades. Concerning sex predominance for tongue base schwannomas, Some authors reported that there was no sex difference ${ }^{[12,20,30]}$, while others claim that there is female predominance $(1.6: 1)^{[39]}$. This was similar to our review that showed higher incidence among females (1.5:1).

They are usually solitary but multifocal lesions have also been reported. Multiple lesions occur in: (1) neurofibromatosis type 1 (NF1) or type 2 (NF2); (2) in schwannomatosis which is the third major form of neurofibromatosis and is characterized by multiple nonvestibular schwannomas with no other signs of $\mathrm{NF}^{[1]}$. Nevertheless, the incidence of schwannomas in the setting of NF-1 is very rare. Consequently, a thorough general examination to check for the presence of other characteristic signs of von Recklinghausen's syndrome is not necessary ${ }^{[39,40]}$.

Malignant schwannomas are an exceptionally rare. They account for $5 \%$ of all soft tissue sarcomas. Of these, only $8-14 \%$ are in the head and neck ${ }^{[41]}$.

Although there is a rare possibility of malignant transformation of a solitary extracranial head and neck schwannoma, it has been reported in one case in the tongue. To support a diagnosis of malignant transformation in benign schwannoma, the following features should be confirmed: (a) the benign schwannoma tumor demonstrates unequivocal malignant foci as manifested by the presence of increased cellularity, numerous mitoses, anaplastic cells, and invasiveness; (b) transitional features between malignant and benign areas can be seen; and (c) no evidence of von Recklinghausen's disease ${ }^{[12,42,43]}$.

Clinically, schwannomas are indistinguishable from other intra-oral slow growing encapsulated smooth submucosal swellings like neurofibromas, granular cell tumor, salivary gland tumors, traumatic fibroma, leiomyomas, rhabdomyomas, lymphangiomas, haemangiomas, epidermoid cysts, lipomas, inflammatory lesions and ectopic lingual thyroid ${ }^{[1,39,44]}$.

Histopathologically, schwannomas are classified into seven subtypes: classical (Verocay), cellular, plexiform, cranial nerve, melanotic, degenerated (ancient), and granular cell schwannoma ${ }^{[45]}$. The characteristic histological features of schwannomas are: encapsulated; and alternating hypercelullar spindle cell area (Antoni A; densely packed, elongated, palisaded nuclei, spindle, Schwann cells) and hypocelullar round cell area, (Antoni B; small round cells, within a myxoid stroma). Free bands of collagenous hyalinised core between rows of nuclei constitute the Verocay bodies. Vascularity is not a prominent feature, and necrosis and mitotic activity are seldom encountered. Diagnosis can be aided by immunohistochemical markers, for S-100, Leu-7 antigen, vimentin, and glial fibrillary acidic protein which supports the Schwann cell origin of these tumors ${ }^{[12]}$.

The differentiation between schwannoma and neurofibroma is essential because solitary neurofibroma may be a manifestation of neurofibromatosis which has a $10-15 \%$ lifetime risk of malignant transformation. Such differences entail characteristic histologic findings of prominent collagenous or myxoid stroma, scattered inflammatory cells, positive S-100 staining (30-50\%), and variable CD34 positivity ${ }^{[44]}$.

Radiologically, most schwannomas on CT appear as well-circumscribed, dense, homogeneous softtissue masses which exhibit contrast enhancement. 
Calcification or hemorrhage is uncommon, but cystic or fatty degeneration is frequent. The use of CT is less than ideal because it can be limited by bone artifact, especially in smaller lesions. Its true value lies in its ability to determine the amount adjacent bony damage that has occurred secondarily to schwannoma growth. MRI is superior to CT for schwannomas, because of its increased tissue contrast and spatial resolution when compared to $\mathrm{CT}$, not degraded by dental amalgam or the beamhardening artifacts, allows a more precise localization and better visualization of the relations to other structures, as well as a more accurate measurement of tumor size. Most schwannomas appear hypointense or isointense relative to muscle on T1-weighted images, hyperintense on T2weighted images, and show strong enhancement after contrast administration. Moreover, these tumors usually appear smooth, well demarcated, and do not invade the surrounding musculature ${ }^{[30,46]}$.

The goal of surgical therapy is complete pericapsular excision. If the nerve of origin is visualized, an attempt should be made to separate it carefully to preserve function, however, this is sometimes not possible. If this is accomplished, recurrence is rare. Different surgical approaches have been described for tongue base schwannomas. They include trans-oral (robotic surgery, $\mathrm{CO} 2$ Laser excision, or using diathermy $)^{[2-9,12,14-17,19,21-}$ 23,25-29,31,32,34], submandibular pull-through ${ }^{[13]}$, suprahyoid (trans-hyoid) lateral pharyngotomy approaches ${ }^{[18,20,24,30,33,34]}$ and midline mandibulotomy and tongue split ${ }^{[10,11]}$. In our review, we found that most lesions were excised transoral without any significant intra or postoperative morbidities $(76.7 \%)$. This could be explained by many advantages characterizing this approach including avoidance of external scar, preservation of sensation and function, earlier swallow rehabilitation and decreased frequency of fistula formation. However, it has the disadvantage of limited exposure and less optimal visualization of deeper structures. Pharyngotomy approach has the advantage of preservation of mandibular continuity, avoidance of lip splitting incision and ability to close defect primarily ${ }^{[30]}$.

\section{CONCLUSIONS}

Despite their rarity, tongue base schwannomas should be included wheneverabenign submucosalswelling is suspected. The final diagnosis should be made after histopathological examination supported by immunohistochemical analysis in certain cases. Most lesions could be safely excised via transoral access except those with deep extension towards the floor of the mouth or vallecula; an open approach would be required. The recurrence and malignant transformation are exceptionally very rare.

\section{CONFLICT OF INTEREST:}

We have no conflict of interest

\section{REFERENCES}

1. Moreno-Garcia C, Pons-Garcia MA, GonzalezGarcia R, Monje-Gil F. Schwannoma of tongue. J Maxillofac Oral Surg. 2014;13:217-21.

2. Badar Z, Farooq Z, Zaccarini D, Ezhapilli SR. Tongue base schwannoma: differential diagnosis and imaging features with a case presentation. Radiology case reports. 2016;11:336-40.

3. Mehrzad H, Persaud R, Papadimitriou N, Kaniyur $\mathrm{S}$, Mochloulis G. Schwannoma of tongue base treated with transoral carbon dioxide laser. Lasers Med Sci. 2006;21:235-37.

4. Ashish G. Transoral Laser Excision of Schwannoma in Base of Tongue: A Case Report with Review of Literature. Otorhinolaryngology Clinics: An International Journal. 2015;7:68-71.

5. Ballesteros F, Vilaseca I, Blanch JL, Gaspa A, Bernal-Sprekelsen M. Base of tongue neurilemmoma: excision by transoral laser microsurgery. Acta Otolaryngol. 2007; 127:1005-7.

6. Bassichis BA, McClay JE. Pedunculated neurilemmoma of the tongue base. Otolaryngology - Head and Neck Surgery. 2004;130:639-41.

7. Batra K, Rai AK, Chaudhary N, Topno S. Two cases of neurilemmoma of the tongue. ENT: Ear, Nose \& Throat Journal. 2007; 86:679-81

8. Batra UB, Usha G, Gogia AR. Anesthetic management of schwannoma of the base of the tongue. J Anaesthesiol Clin Pharmacol 2011;27:241.

9. Chadwick D. Neurilemmoma of the tongue. The Journal of Laryngology \& Otology. 1964; 78:959-62.

10. Chandak N, Harkut R. Neurilemmoma of posterior third of tongue. Indian Journal of Otolaryngology and Head \& Neck Surgery. 1972;24:118-20.

11. Chari P, Balakrishnan C. Neurilemmoma of the base of the tongue. Indian Journal of Otolaryngology and Head \& Neck Surgery. 1979;31:133.

12. Cohen M, Wang MB. Schwannoma of the tongue: two case reports and review of the literature. Eur Arch Otorhinolaryngol. 2009;266:1823-29. 
13. de Bree R, Westerveld G-J, Smeele LE. Submandibular approach for excision of a large schwannoma in the base of the tongue. Eur Arch Otorhinolaryngol. 2000;257:283-86.

14. Fan S, Zhang D-m, Chen W-1. EndoscopyAssisted Resection of Benign Lesions on the Base of the Tongue via the Transoral Approach Using a Harmonic Scalpel. J Oral Maxillofac Surg. 2017; 75:2242-47.

15. Farzadnia M, Bakhshaee M. Schwannoma of the tongue base: A case report. Iranian Journal of Pathology. 2007;2:119-22

16. Gopalakrishnan SN, Jayaraman NK, SA LA. Schwannoma over tongue base-Case report and review. Online Journal of Otolaryngology. $2016 ; 6$

17. Gupta TD, Brasfield RD, Strong EW, Hajdu SI. Benign solitary schwannomas (neurilemomas). Cancer. 1969;24:355-66

18. Hsu Y-C, Hwang C-F, Hsu R-F, Kuo F-Y, Chien $\mathrm{C}-\mathrm{Y}$. Schwannoma (neurilemmoma) of the tongue. Acta Otolaryngol. 2006;126:861-65.

19. Kamath MP, Kini H, Shenoy SV, Deviprasad D, Prakash N, Pai R. Schwannoma of the base of tongue-A rare presentation. Egyptian Journal of Ear, Nose, Throat and Allied Sciences. 2014; 15:61-64.

20. Kurup S, Thankappan K, Krishnan N, Nair PP. Intraoral schwannoma-a report of two cases. BMJ Case Rep. 2012;2012:bcr1220115389.

21. Nakasato T, Kamada Y, Ehara S, Miura Y. Multilobular neurilemmoma of the tongue in a child. American journal of neuroradiology. 2005;26:421-23.

22. Nisa L, von Büren T, Tiab A, Giger R. Giant plexiform schwannoma of the tongue. Case Rep Otolaryngol. 2011; 2011: 762524

23. Purohit JP, Selvaraj S, Purohit K, Kumar $\mathrm{V}$, Moshahary S. Atypical presentation of neurilemmoma of base of tongue-a case report. JOURNAL OF EVOLUTION OF MEDICAL AND DENTAL SCIENCES-JEMDS. 2017;6:255-57.

24. Sawhney R, Carron MA, Mathog RH. Tongue base schwannoma: report, review, and unique surgical approach. Am J Otolaryngol. 2008;29:119-22.
25. Sharma S, Rai G. Schwannoma (neurilemmoma) on the base of the tongue: A rare clinical case. The American journal of case reports. 2016;17:203.

26. Singh GB, Arora R, Sunil Garg MS D, Aggarwal K. Base of tongue schwannoma. Ear, Nose \& Throat Journal. 2015;94:306.

27. Singh HP, Kumar S, Verma N, et al. Schwannoma base of tongue: report of a rare case and review of literature. Int J Head Neck Surg. 2013;4:133-35

28. Sinha S, Samuel K. Neurilemmoma of tongue. The Journal of Laryngology \& Otology. 1971;85:623-26.

29. Spandow O, Fagerlund M, Bergmark L, Boquist L. Clinical and histopathological features of a large parapharyngeal neurilemmoma located at the base of the tongue. ORL. 1999;61:25-30.

30. Tandon S, Meher R, Chopra A, et al. Tongue Base Schwannoma. Indian Journal of Otolaryngology and Head \& Neck Surgery. 2016;68:1-4.

31. Verghese S, Rupa V, Kurian S. Schwannoma of the base of tongue. Indian Journal of Otolaryngology and Head and Neck Surgery. 1996;48:228-29.

32. Vivek S, Acharya D, Ravichandra G, Vinayaka U. Tongue base Schwannoma: a rare entity. JOURNAL OF EVOLUTION OF MEDICAL AND DENTAL SCIENCES-JEMDS. 2015;4:3389-94.

33. Ying B, Zhu S, Qiao Y, et al. Surgical approaches for tongue base schwannoma. J Craniofac Surg. 2013;24:e9-e11.

34. Ying YLM, Zimmer LA, Myers EN. Base of tongue schwannoma: a case report. The Laryngoscope. 2006;116:1284-87.

35. Sinkkonen ST, Hildén O, Hagström J, Leivo I, Bäck LJ, Mäkitie AA. Experience of head and neck extracranial schwannomas in a whole population-based single-center patient series. Eur Arch Otorhinolaryngol. 2014;271:3027-34.

36. Wippold F, Lämmle $\mathrm{M}$, Anatelli F, Lennerz J, Perry A. Neuropathology for the neuroradiologist: palisades and pseudopalisades. American journal of neuroradiology. 2006;27:2037-41.

37. Abreu I, Roriz D, Rodrigues P, Moreira Â, Marques C, Alves FC. Schwannoma of the tongue-A common tumour in a rare location: A case report. European Journal of Radiology Open. 2017;4:1-3. 
38. Bansal R, Trivedi P, Patel S. Schwannoma of the tongue. Oral Oncology Extra. 2005;41:15-17.

39. Lukšić I, Müller D, Virag M, Manojlović S, Ostović KT. Schwannoma of the tongue in a child. Journal of Cranio-Maxillofacial Surgery. 2011;39:441-44.

40. Ahlawat S, Blakeley J, Montgomery E, Subramaniam RM, Belzberg A, Fayad LM. Schwannoma in neurofibromatosis type 1: a pitfall for detecting malignancy by metabolic imaging. Skeletal Radiol. 2013;42:1317-22.

41. Colreavy M, Lacy P, Hughes J, et al. Head and neck schwannomas-a 10 year review. The Journal of Laryngology \& Otology. 2000;114:119-24.

42. Kun Z, Dao-Yi Q, Kui-Hua Z. A comparison between the clinical behavior of neurilemmomas in the neck and oral and maxillofacial region. $\mathrm{J}$ Oral Maxillofac Surg. 1993;51:769-71.
43. Piatelli A, Angelone A, Pizzicannella G, Piatelli M. Malignant schwannoma of the tongue. Report of a case and review of the literature. Acta Stomatol Belg. 1984;81:213.

44. Catalfamo L, Lombardo G, Nava C, et al. Tongue schwannoma: clinicopathological findings. J Craniofac Surg. 2011;22:1158-61.

45. Erlandson RA. Peripheral nerve sheath tumors Ultrastruct Pathol. 1985;9:113-22.

46. Jadwani S, Bansod S, Mishra B. Intraoral schwannoma in retromolar region. J Maxillofac Oral Surg. 2012;11:491-94. 